\title{
Prevalence and Determinants of Tinnitus in the Italian Adult Population
}

\author{
Silvano Gallus ${ }^{\mathrm{a}}$ Alessandra Lugo ${ }^{\mathrm{b}}$ Werner Garavello ${ }^{c}$ Cristina Bosetti ${ }^{\mathrm{a}}$ \\ Eugenio Santoro ${ }^{a}$ Paolo Colombo $^{d}$ Paola Perin ${ }^{\text {e Carlo La Vecchia }}{ }^{b}$ \\ Berthold Langguth $^{f}$
}

${ }^{a}$ Department of Epidemiology, IRCCS - Istituto di Ricerche Farmacologiche 'Mario Negri', ${ }^{b}$ Department of Clinical Sciences and Community Health, University of Milan, 'Department of Surgery and Translational Medicine, University of Milano-Bicocca, distituto DOXA, Worldwide Independent Network/Gallup International Association

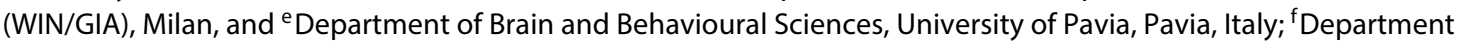
of Psychiatry and Psychotherapy, University of Regensburg, Regensburg, Germany

\section{Key Words}

Tinnitus · Prevalence · Risk factors · Italy · Representative survey Epidemiology

\begin{abstract}
Background: Limited, outdated, and poor quality data are available on the prevalence of tinnitus, particularly in Italy. Methods: A face-to-face survey was conducted in 2014 on 2,952 individuals, who represented the Italian population aged 18 or more ( 50.6 million). Any tinnitus was defined as the presence of ringing or buzzing in the ears lasting for at least $5 \mathrm{~min}$ in the previous 12 months. Results: Any tinnitus was reported by $6.2 \%$ of Italian adults, chronic tinnitus (i.e. for more than 3 months) by $4.8 \%$, and severe tinnitus (i.e. which constitutes a big or very big problem) by $1.2 \%$. The corresponding estimates for the population aged $\geq 45$ years were $8.7,7.4$ and $2.0 \%$, respectively. Multivariable analysis on population aged $\geq 45$ years revealed that old age (odds ratio $(O R)=4.49$ for $\geq 75$ vs. $45-54$ years) and obesity (OR $=$ 2.14 compared to normal weight) were directly related to any tinnitus, and high monthly family income $(O R=0.50)$ and moderate alcohol consumption ( $\mathrm{OR}=0.59$ for $<7$ drinks/ week vs. non-drinking) were inversely related. Conclusions: This is the first study on tinnitus prevalence among the gen-
\end{abstract}

eral Italian adult population. It indicates that in Italy tinnitus affects more than 3 million adults and is felt as a major problem by more than 600,000 Italians, mostly aged 45 years or more.

(c) 2015 S. Karger AG, Basel

\section{Introduction}

Tinnitus, a symptom of various underlying pathologies, is defined as the perception of sound, typically a ringing, buzzing, or whistling sound, in the absence of a corresponding acoustic external stimulus $[1,2]$.

Inadequate and poor-quality data are available on the epidemiology of tinnitus (e.g. prevalence, aetiology, and potential treatments). This is, at least in part, a consequence of the subjective nature of tinnitus assessment, the heterogeneity of the question used to define the presence of tinnitus, and the large variety of tinnitus characteristics [3] and associated disorders [4].

Knowledge on the burden of tinnitus in the general adult population comes from a few large prospective studies, mostly from northern Europe and the United States, providing data on tinnitus incidence [5-7]. To our knowledge, only 20 previous studies from 14 countries reported infor- 
mation on adult tinnitus prevalence using surveys recorded at a national or sub-national level. Online supplementary table 1 (www.karger.com/doi/10.1159/000431376) shows the summary results from those surveys [5, 8-25]. Prevalence of tinnitus in adults ranged between 5 and $30 \%$ and that of severe tinnitus from less than 1 to $7 \%$.

In Italy, besides a few case series [26-30] or studies on selected professional subgroups [31], information on tinnitus prevalence comes from 2 surveys. One investigation, conducted in Milan in 1981 on 1,473 adults, showed a chronic tinnitus prevalence of $12 \%$ and severe tinnitus prevalence of 3\% [24, 32]. Another survey, conducted in 5 Italian provinces in the 1990s on a sample of 2,216 adults, reported a prevalence of chronic tinnitus of $14.5 \%$ $[25,32]$. Both surveys showed a relatively high prevalence of tinnitus, but since they were conducted in selected areas we cannot consider them to be representative of the Italian general population.

In order to update the information on tinnitus in Italy and to determine its socio-demographic and other individual-level correlates, we analysed data from a representative survey of Italian adults conducted in 2014. Moreover, we compared tinnitus prevalence with the other available prevalence estimates worldwide.

\section{Methods}

In collaboration with DOXA - the Italian branch of the worldwide Independent Network/Gallup International Association during February to April 2014, we conducted a face-to-face survey using a standardized methodology $[33,34]$. The study sample consisted of 2,952 individuals (1,413 men and 1,539 women) aged 18 or more, representative of the Italian adult population (i.e. 50.6 million adults) in terms of sex, age, geographic area, and socioeconomic characteristics. Participants were selected through a representative multistage random sampling. The first stage was used to select municipalities (the smallest Italian administrative division) in all of the 20 Italian regions (the largest Italian administrative division). Thus, taking region and size as criteria, we identified 116 municipalities, representative of the Italian universe of municipalities. In the second stage, in each municipality, an adequate number of electoral wards was randomly extracted (each ward corresponding to a given district of each municipality), so that the various types of more or less affluent areas of the municipality were represented in the right proportions (i.e. central and suburban districts, outskirts and isolated houses). In the third stage, knowing the demographic structure of the Italian population, adequate sex- and age-specific numbers of individuals were randomly sampled from electoral rolls. Unavailable participants were replaced by their neighbours with the same sex and age group. Statistical weights were used to assure the representativeness of the Italian population aged 18 years or more.

Ad hoc trained interviewers conducted interviews using a structured questionnaire in the context of a computer-assisted personal interview (CAPI). All interviews were conducted in the houses of the selected individuals who accepted to participate to the study. Besides general information on demographic and socioeconomic characteristics, we collected data on anthropometric characteristics, tobacco smoking, and alcohol drinking. The questionnaire also included 3 direct questions about tinnitus [35]. Participants were asked about the presence of tinnitus as follows: 'in the past 12 months, have you been bothered by ringing or buzzing in your ears or head that lasted for 5 min or more?' Those who answered 'yes' were enquired about their experience with tinnitus with 2 further questions: the first one (i.e. 'How long have you been bothered by this ringing or buzzing in your ears or head?') was used to detect 'chronic tinnitus', defined as tinnitus duration of 3 months or more; the second one (i.e. 'How much of a problem is this ringing or buzzing in one or both ears or in your head?') was used to assess severity of tinnitus: mild tinnitus was defined as reporting 'no problem' or 'a small problem', moderate tinnitus as reporting 'a moderate problem', and severe tinnitus as reporting 'a big problem' or 'a very big problem.'

Education was categorized into low (no qualification up to middle school diploma), intermediate (high school), and high (university). Geographic area was categorized as northern, central, and southern Italy. Ever smokers (current and ex-smokers) were participants who had smoked 100 or more cigarettes in their lifetime. Ex-smokers were participants who had quit smoking at least 1 year before the study, and current smokers were individuals continuing smoking or having stopped less than 1 year before the study. Alcohol consumption was computed as the sum of the number of drinks/week (around $12 \mathrm{~g}$ of alcohol) of 4 different types of alcoholic beverages (i.e. beer, wine, spirits, and digestives). This variable was then categorized into no alcohol drinking, consumption of $<7$ drinks per week (median value), and consumption of $\geq 7$ drinks per week. Body mass index (BMI) was computed as the ratio between self-reported weight $(\mathrm{kg})$ and height $\left(\mathrm{m}^{2}\right)$, and categorized into: underweight and normal weight (BMI $\left.<25.0 \mathrm{~kg} / \mathrm{m}^{2}\right)$, overweight $\left(25.0 \leq \mathrm{BMI}<30.0 \mathrm{~kg} / \mathrm{m}^{2}\right)$, and obese (BMI $\left.\geq 30.0 \mathrm{~kg} / \mathrm{m}^{2}\right)$. The net monthly family income was categorized according to tertiles in the overall population aged $\geq 45$ years $(<1,160 \mathrm{EUR} /$ month, $1,160-1,939 \mathrm{EUR} /$ month, $\geq 1,940 \mathrm{EUR} / \mathrm{month}$ ).

\section{Statistical Analyses}

Given the rarity of (severe) tinnitus among the young (18-44 years), we limited the multivariate analyses to middle-age and elderly adults ( $\geq 45$ years). Odds ratios (ORs) for any, chronic and severe tinnitus, and corresponding 95\% confidence intervals (CIs), were estimated using unconditional multiple logistic regression after adjustment for sex, age, level of education, geographic area, smoking status, alcohol consumption and BMI. All the analyses were performed with the SAS, version 9.2, statistical package (SAS Institute).

\section{Results}

Table 1 shows the prevalence of tinnitus overall and according to its duration and severity. Among 2,952 Italian adults, $6.2 \%$ reported tinnitus in the past 12 months. Any tinnitus prevalence was $6.0 \%$ in men and 
Table 1. Percent prevalence ${ }^{\mathrm{a}}$ of tinnitus, and corresponding $95 \% \mathrm{CI}$, overall and by sex and age group, according to the duration of symptom and its severity, among 2,952 adults, Italy, 2014

\begin{tabular}{|c|c|c|c|c|c|c|c|c|c|c|c|c|}
\hline & \multicolumn{2}{|c|}{ Overall } & \multicolumn{4}{|l|}{ Sex } & \multicolumn{6}{|c|}{ Age group, years } \\
\hline & \multirow[t]{2}{*}{$\%$} & \multirow[t]{2}{*}{$95 \% \mathrm{CI}$} & \multicolumn{2}{|c|}{ men } & \multicolumn{2}{|c|}{ women } & \multicolumn{2}{|c|}{$18-44$} & \multicolumn{2}{|c|}{$45-64$} & \multicolumn{2}{|l|}{$\geq 65$} \\
\hline & & & $\%$ & $95 \% \mathrm{CI}$ & $\%$ & $95 \% \mathrm{CI}$ & $\%$ & $95 \% \mathrm{CI}$ & $\%$ & $95 \% \mathrm{CI}$ & $\%$ & $95 \% \mathrm{CI}$ \\
\hline Any tinnitus & 6.2 & $5.3-7.0$ & 6.0 & $4.7-7.2$ & 6.4 & $5.2-7.6$ & 2.7 & $1.8-3.6$ & 5.9 & $4.5-7.4$ & 12.3 & $9.9-14.6$ \\
\hline \multicolumn{13}{|l|}{ Tinnitus duration } \\
\hline Acute tinnitus ( $<3$ months) & 1.3 & $0.9-1.7$ & 1.1 & $0.5-1.6$ & 1.6 & $1.0-2.2$ & 1.4 & $0.7-2.1$ & 1.3 & $0.6-2.1$ & 1.2 & $0.4-2.0$ \\
\hline Chronic tinnitus ( $\geq 3$ months) & 4.8 & 4.1-5.6 & 4.9 & $3.8-6.0$ & 4.8 & $3.7-5.9$ & 1.3 & $0.7-1.9$ & 4.6 & $3.3-5.9$ & 11.1 & $8.8-13.3$ \\
\hline \multicolumn{13}{|l|}{ Tinnitus severity } \\
\hline Mild tinnitus & 2.9 & $2.3-3.5$ & 3.1 & $2.2-4.1$ & 2.6 & $1.8-3.4$ & 2.1 & $1.3-2.9$ & 2.8 & $1.8-3.9$ & 4.3 & $2.8-5.7$ \\
\hline No problem & 0.5 & $0.2-0.7$ & 0.2 & $0.0-0.5$ & 0.7 & $0.3-1.1$ & 0.6 & $0.1-1.0$ & 0.3 & $0.0-0.6$ & 0.7 & $0.1-1.3$ \\
\hline Small problem & 2.4 & $1.8-3.0$ & 2.9 & $2.0-3.8$ & 1.9 & $1.2-2.6$ & 1.5 & $0.8-2.2$ & 2.6 & $1.6-3.6$ & 3.6 & $2.3-5.0$ \\
\hline \multicolumn{13}{|l|}{ Moderate tinnitus } \\
\hline Moderate problem & 2.1 & $1.6-2.6$ & 2.0 & $1.3-2.8$ & 2.1 & $1.4-2.8$ & 0.5 & $0.1-0.9$ & 2.0 & $1.1-2.8$ & 4.8 & $3.2-6.3$ \\
\hline Severe tinnitus & 1.2 & $0.8-1.6$ & 0.8 & $0.3-1.3$ & 1.6 & $1.0-2.3$ & 0.1 & $0.0-0.3$ & 1.2 & $0.5-1.8$ & 3.2 & $1.9-4.5$ \\
\hline Big problem & 1.0 & $0.6-1.3$ & 0.4 & $0.1-0.7$ & 1.5 & $0.9-2.1$ & 0.0 & - & 0.9 & $0.3-1.5$ & 2.7 & $1.5-3.8$ \\
\hline Very big problem & 0.3 & $0.1-0.5$ & 0.4 & $0.1-0.8$ & 0.1 & $0.0-0.3$ & 0.1 & $0.0-0.3$ & 0.3 & $0.0-0.6$ & 0.6 & $0.0-1.1$ \\
\hline
\end{tabular}

a Sometimes the sum does not add up to the total due to decimal approximations. The estimates for any, chronic, and severe tinnitus are given in bold.

$6.4 \%$ in women, and increased from $2.7 \%$ in individuals aged $18-44$ years, to $5.9 \%$ at $45-64$ years, up to $12.3 \%$ at $\geq 65$ years. Any tinnitus prevalence was $10.8 \%$ in individuals aged $65-74,13.2 \%$ in those aged $75-84$, and $27.4 \%$ in those aged $\geq 85$ years. Overall, the prevalence of chronic tinnitus was $4.8 \%$. This prevalence was similar in men $(4.9 \%)$ and women $(4.8 \%)$, and increased with increasing age (1.3\% in participants aged $18-44$ years, $4.6 \%$ in $45-64$, and $11.1 \%$ in participants aged $\geq 65$ years). According to severity, $2.9 \%$ of adults reported a mild, $2.1 \%$ a moderate, and $1.2 \%$ a severe tinnitus (1.0\% reported that tinnitus was a 'big problem' and $0.3 \%$ a 'very big problem'). Prevalence of severe tinnitus was $0.8 \%$ in men and $1.6 \%$ in women, and was $0.1 \%$ in $18-44$ years participants, $1.2 \%$ in $45-64$ years, and $3.2 \%$ in $\geq 65$ years. Among adults with severe tinnitus, $2.7 \%$ were aged $18-44$ and $97.3 \%$ were aged $\geq 45$ years.

Table 2 shows the ORs for any, chronic and severe tinnitus, according to selected socio-demographic characteristics in the Italian population aged $\geq 45$ years. Any tinnitus increased with increasing age: as compared to participants aged $45-54$ years, the OR for those aged $\geq 75$ was 4.49 (95\% CI: 2.34-8.62). An inverse trend was observed according to family income: as compared to individuals with income $<1,160 \mathrm{EUR} /$ month, the OR for those with income $\geq 1,940 \mathrm{EUR} /$ month was 0.50 (95\% CI: 0.29-0.85).
A higher prevalence of any tinnitus was observed in widowed (OR: 1.88; 95\% CI: 1.15-3.06) and divorced/separated participants (OR: 2.32; 95\% CI: 1.21-4.43) as compared to married participants. No significant relation with any tinnitus was observed according to sex and municipality size. Chronic tinnitus patterns broadly reflected those of any tinnitus. Based on the severity of the tinnitus, women more frequently reported severe tinnitus compared to men (OR: 3.26; 95\% CI: 1.28-8.31). A significant direct trend was observed in severe tinnitus prevalence according to age: the OR compared to individuals aged $<55$ years was 9.59 (95\% CI: $2.24-40.96)$ for participants aged $\geq 75$ years ( $p$ for trend $=0.002)$. Significant inverse trends were observed with family income $(\mathrm{p}=$ $0.011)$ and municipality size $(\mathrm{p}=0.022)$. No specific pattern in chronic and severe tinnitus was observed based on the level of education of the participants and geographic area in which they were located.

When compared to abstainers, the OR of any tinnitus was 0.59 (95\% CI: 0.36-0.98) for moderate and 1.38 (95\% CI: 0.87-2.21) for high alcohol drinkers (table 3). Corresponding ORs for severe tinnitus were 0.19 (95\% CI: 0.040.89 ), and 1.69 (95\% CI: 0.72-3.97), respectively. A significant direct trend was observed according to BMI ( $\mathrm{p}=$ 0.004): as compared to underweight and normal weight subjects, the OR of any tinnitus for overweight was 1.49 
Table 2. Percent prevalence of any, chronic, and severe tinnitus among 1,724 adults aged $\geq 45$ years, according to selected socio-demographic characteristics, with corresponding $\mathrm{OR}^{\mathrm{a}}$ and 95\% CI, Italy, 2014

\begin{tabular}{|c|c|c|c|c|c|c|c|}
\hline & \multirow[t]{2}{*}{$\mathrm{n}$} & \multicolumn{2}{|c|}{ Any tinnitus } & \multicolumn{2}{|c|}{ Chronic tinnitus } & \multicolumn{2}{|c|}{ Severe tinnitus } \\
\hline & & $\%$ & OR $(95 \% \mathrm{CI})$ & $\%$ & OR (95\% CI) & $\%$ & OR (95\% CI) \\
\hline \multicolumn{8}{|l|}{ Sex } \\
\hline Men & 792 & 8.3 & $1^{\mathrm{b}}$ & 7.0 & $1^{\mathrm{b}}$ & 1.3 & $1^{\mathrm{b}}$ \\
\hline Women & 932 & 9.0 & $1.43(0.92-2.20)$ & 7.8 & $1.45(0.91-2.32)$ & 2.7 & $3.26(1.28-8.31)$ \\
\hline $55-64$ & 445 & 8.6 & $2.18(1.20-3.95)$ & 7.1 & $2.63(1.32-5.23)$ & 2.0 & $3.57(0.87-14.66)$ \\
\hline $65-74$ & 492 & 10.8 & $2.80(1.55-5.08)$ & 9.9 & $3.79(1.93-7.45)$ & 2.4 & $4.21(1.03-17.17)$ \\
\hline$\geq 75$ & 251 & 15.2 & $4.49(2.34-8.62)$ & 13.4 & $5.87(2.81-12.26)$ & 4.9 & $9.59(2.24-40.96)$ \\
\hline $\mathrm{p}$ for trend & & & $<0.001$ & & $<0.001$ & & 0.002 \\
\hline \multicolumn{8}{|l|}{ Level of education } \\
\hline Low & 934 & 10.1 & $1^{\mathrm{b}}$ & 8.6 & $1^{\mathrm{b}}$ & 2.6 & $1^{\mathrm{b}}$ \\
\hline I tertile $(<1,160$ EUR $)$ & 484 & 12.8 & $1^{\mathrm{b}}$ & 11.2 & $1^{\mathrm{b}}$ & 3.8 & $1^{\mathrm{b}}$ \\
\hline II tertile (1,160-1,939 EUR) & 607 & 9.2 & $0.91(0.59-1.40)$ & 7.8 & $0.88(0.56-1.39)$ & 2.6 & $1.05(0.50-2.21)$ \\
\hline III tertile ( $\geq 1,940$ EUR $)$ & 633 & 5.0 & $0.50(0.29-0.85)$ & 4.1 & $0.49(0.27-0.88)$ & 0.1 & $0.06(0.01-0.57)$ \\
\hline $\mathrm{p}$ for trend & & & 0.015 & & 0.020 & & 0.011 \\
\hline \multicolumn{8}{|l|}{ Marital status } \\
\hline Married & 1,213 & 7.6 & $1^{\mathrm{b}}$ & 6.5 & $1^{\mathrm{b}}$ & 1.3 & $1^{\mathrm{b}}$ \\
\hline Single & 136 & 3.4 & $0.67(0.25-1.78)$ & 3.1 & $0.78(0.28-2.15)$ & 0.4 & $0.46(0.03-6.90)$ \\
\hline Widowed & 262 & 15.2 & $1.88(1.15-3.06)$ & 13.3 & $1.86(1.10-3.12)$ & 5.0 & $2.30(0.94-5.68)$ \\
\hline Divorced/separated & 112 & 11.8 & $2.32(1.21-4.43)$ & 8.4 & $1.85(0.88-3.89)$ & 5.4 & $5.43(1.95-15.10)$ \\
\hline \multicolumn{8}{|l|}{ Geographic area } \\
\hline Northern Italy & 814 & 8.1 & $1^{\mathrm{b}}$ & 7.3 & $1^{\mathrm{b}}$ & 2.2 & $1^{\mathrm{b}}$ \\
\hline
\end{tabular}

a ORs were estimated using unconditional multiple logistic regression models after adjustment for sex, age, level of education, geographic area, smoking status, alcohol drinking, and body mass index; significant figures are given in bold; ${ }^{b}$ reference category.

(95\% CI: 0.99-2.25) and the OR for obese 2.14 (95\% CI: 1.25-3.67). No significant relation was observed according to smoking status for any, chronic or severe tinnitus.

\section{Discussion}

This is the first national representative study providing data on tinnitus prevalence in the Italian adult population. Self-reported prevalence of tinnitus was $6.2 \%$ and that of severe tinnitus was $1.2 \%$. The corresponding estimates for adults aged $\geq 45$ years were 8.7 and $2.0 \%$, and for the elderly (aged $\geq 65$ years) 12.3 and $3.2 \%$, respectively. Only 2 previous studies, conducted more than 2 decades ago, and including selected samples of the adult population in selected areas, investigated tinnitus prevalence in Italy, showing substantially higher prevalence estimates among adults [24, 25, 32].

We found no sex differences in any and chronic tinnitus, while severe tinnitus was more frequent in women. 
Table 3. Percent prevalence of any, chronic and severe tinnitus among 1,724 adults aged $\geq 45$ years, according to smoking status, alcohol consumption, and BMI, and corresponding $\mathrm{OR}^{\mathrm{a}}$ and 95\% CI, Italy, 2014

\begin{tabular}{|c|c|c|c|c|c|c|c|}
\hline & \multirow[t]{2}{*}{$\mathrm{n}$} & \multicolumn{2}{|c|}{ Any tinnitus } & \multicolumn{2}{|c|}{ Chronic tinnitus } & \multicolumn{2}{|c|}{ Severe tinnitus } \\
\hline & & $\%$ & OR (95\% CI) & $\%$ & OR (95\% CI) & $\%$ & OR (95\% CI) \\
\hline Never smokers & 1,097 & 8.4 & $1^{\mathrm{b}}$ & 7.2 & $1^{\mathrm{b}}$ & 2.1 & $1^{\mathrm{b}}$ \\
\hline Current smokers & 312 & 5.2 & $0.64(0.34-1.20)$ & 3.8 & $0.59(0.29-1.19)$ & 1.1 & $0.94(0.29-3.09)$ \\
\hline Ex-smokers & 314 & 13.0 & $1.50(0.96-2.34)$ & 11.7 & $1.53(0.96-2.46)$ & 2.6 & $1.51(0.61-3.76)$ \\
\hline$<7$ drinks/week & 483 & 5.0 & $0.59(0.36-0.98)$ & 4.4 & $0.60(0.35-1.03)$ & 0.4 & $0.19(0.04-0.89)$ \\
\hline$\geq 7$ drinks/week & 500 & 10.7 & $1.38(0.87-2.21)$ & 8.8 & $1.29(0.78-2.14)$ & 2.6 & $1.69(0.72-3.97)$ \\
\hline $\mathrm{p}$ for trend & & & 0.307 & & 0.479 & & 0.447 \\
\hline \multicolumn{8}{|l|}{ BMI categories ${ }^{c}$} \\
\hline Under/normal weight $\left(\mathrm{BMI}<25 \mathrm{~kg} / \mathrm{m}^{2}\right)$ & 741 & 6.1 & $1^{\mathrm{b}}$ & 5.0 & $1^{\mathrm{b}}$ & 1.4 & $1^{\mathrm{b}}$ \\
\hline Overweight $\left(25 \leq \mathrm{BMI}<30 \mathrm{~kg} / \mathrm{m}^{2}\right)$ & 642 & 10.5 & $1.49(0.99-2.25)$ & 9.1 & $1.56(1.00-2.44)$ & 3.2 & $1.99(0.91-4.39)$ \\
\hline
\end{tabular}

${ }^{a}$ ORs were estimated using unconditional multiple logistic regression models after adjustment for sex, age, level of education, geographic area, smoking status, alcohol drinking, and BMI; significant figures are given in bold; ${ }^{b}$ reference category; ${ }^{c}$ the sum does not add up to the total because of some missing values.

Inconsistent results have been reported according to sex differences. In fact, most previous studies, but not all [10, 20], showed higher tinnitus prevalence in men than in women $[5,14,19,36]$.

A direct and steady relationship between age and prevalence of tinnitus was observed in the present as in other studies $[19,21]$, suggesting that tinnitus is a symptom peculiar of the elderly. Some studies, however, observed a plateau of tinnitus prevalence around 60-70 years, and a subsequent decline in older age groups $[9,10,12]$.

Low socioeconomic status has been reported as a potential risk factor for tinnitus in various studies $[9,10,16$, 36]. We confirmed this observation, showing a consistent and significant inverse relation with income, whose magnitude was significantly stronger for severe tinnitus rather than for any tinnitus. Accordingly, our data are compatible with higher (severe) tinnitus rates among residents in municipalities with a relatively small population size. This is in agreement with a survey from China, showing a higher tinnitus prevalence in rural than in urban areas [18], although in Egypt the opposite was observed [22]. A few studies investigated the relationship between marital status and tinnitus, showing no significant difference [21,36]. Conversely, we found that divorced or separated participants had more frequently any, and, in particular, severe tinnitus than married ones.
Both low income [37] and divorce/loss of partner [38] are likely to be associated with high stress and anxiety, which in turn have been strongly correlated with tinnitus [39]. Lower income could also correlate with different exposure to environmental noises [40] and consequent hearing loss, which is thought to be an essential triggering factor in tinnitus onset [4].

We found no significant difference in tinnitus prevalence according to smoking status, confirming findings from most other studies $[17,20,21,36]$. Only a few surveys reported a higher prevalence of tinnitus in current than in never smokers $[9,10]$.

As regards alcohol consumption, moderate drinkers showed the lowest tinnitus prevalence. This is consistent with a study from Norway showing a 10 to $15 \%$ reduction of tinnitus prevalence in moderate alcohol consumers [9], and with a US study showing a substantial reduction of tinnitus prevalence in female alcohol drinkers [41]. The observed relation with alcohol reminds to the well-known J-shaped risk curve between alcohol and the risk of myocardial infarction or other cardiovascular diseases [4244]. Indeed a few studies showed that tinnitus and cardiovascular diseases share several risk factors [10, 41], supporting the hypothesis that a healthy microvascular system in the inner ear [41], cochlear nerve [45] and central auditory system (which is responsible for tinnitus 
chronicization) [4] may reduce the risk of tinnitus. Other studies, however, did not find any relation between alcohol drinking and risk of tinnitus [17, 20, 21, 36].

Prevalence of any and chronic, but not severe, tinnitus was highest among obese compared to normal weight subjects. High BMI was reported as a possible risk factor for tinnitus [9], but most studies showed no consistent relation with overweight/obesity [10, 17, 20, 21, 36].

We observed one of the lowest prevalence estimates of tinnitus (any or severe) worldwide (online suppl. table 1). Our tinnitus prevalence was similar only to those observed in Japan [17], Egypt [22], and Iran [19], but appreciably lower than those found in North America [10], Australia [12], Northern Europe [5, 14, 16], and Korea [20, 21]. Comparisons between different surveys are difficult to make, due to the heterogeneity in terms of age range of the population studied and the lack of a standard and validated definition of tinnitus $[17,21,36]$. We decided to use the definition of tinnitus adopted in the NHANES study [35], which assessed the presence of tinnitus over the past 12 months and not only at the time of interview. This assessment tool may therefore have led to an overestimation of current tinnitus prevalence. Comparisons are also complicated because of the difference in the demographic structure of various populations. The large worldwide heterogeneity in the prevalence of tinnitus may be related to different lifestyles, including dietary, habits [46]. The Mediterranean diet, characterized by a high monounsaturated/saturated fat ratio, a relatively high consumption of cereals, legumes, fruit and vegetables, and fish, a moderate consumption of alcohol, and a low consumption of meat and meat products, and milk and dairy products, has been shown to reduce obesity [47], and prevent cardiovascular [48, 49], cancer [50], and overall mortality and morbidity $[51,52]$. In Italy, the level of adherence to the Mediterranean diet is still relatively high [53]. Also habitual diets of Egypt, Iran, and Japan (i.e. the other countries with relatively low rates of tinnitus) have been shown to share some characteristics of a Mediterranean-like dietary pattern [54]. It is possible that some aspects of the Mediterranean diet may, at least partially, prevent tinnitus. This hypothesis is corroborated by our findings of a favorable effect of moderate alcohol consumption and of an unfavorable effect of obesity on tinnitus. These results should however be confirmed by analytical epidemiological studies, including case-control and cohort studies, providing data on incident cases $[1,10]$. Differences in genetic susceptibility to hearing loss and in the levels of exposure to noise or chemical-induced hearing loss [55] may also have a role in the heterogeneity of tinnitus prevalence estimates observed in various countries.
This is the largest study on tinnitus prevalence in Italy and the first one conducted on a representative sample at the national level. Our sample size was satisfactorily large to derive stable estimates on a relatively frequent condition as any tinnitus and to assess differences in tinnitus prevalence between various subpopulations using a multivariate analysis, after allowance for several covariates. However, given the rarity of severe tinnitus (1.2\%), the statistical power of our sample is inappropriate to observe differences among those with severe tinnitus $(n=36)$ in terms of individual-level characteristics. Moreover, a shortcoming that was present in all population surveys was that information on tinnitus was self-reported, due to the difficulties to objectively detect/diagnose tinnitus. Other potential limitations were those inherent to the cross-sectional design, where it was not possible to establish the mechanisms by which tinnitus and its identified correlates mutually interact $[56,57]$.

In conclusion, in 2014 tinnitus affected more than 3 million Italian adults, and severely impaired the quality of life of more than 600,000 Italian adults, mostly aged 45 years or more. Our data also showed that socioeconomic and anthropometric characteristics, and selected lifestyle habits may have a role on tinnitus prevalence. Our investigation added relevant knowledge on a condition for which inappropriate data on aetiologic factors and no treatments are available today $[1,2]$.

\section{Acknowledgements and Funding}

We thank Mr. Ottorino Savani of the Italian Association of Tinnitus (AIT-Onlus) for his contribution in the understanding of tinnitus in Italy. The survey was conducted with the contribution of the Italian Ministry of Health. The authors declare that there are no conflicts of interest.

\section{References}

1 Baguley D, McFerran D, Hall D: Tinnitus. Lancet 2013;382:1600-1607.

-2 Langguth B, Kreuzer PM, Kleinjung T, De Ridder D: Tinnitus: causes and clinical management. Lancet Neurol 2013;12:920-930.

-3 Tyler R, Coelho C, Tao P, Ji H, Noble W, Gehringer A, Gogel S: Identifying tinnitus subgroups with cluster analysis. Am J Audiol 2008;17:S176-S184.

4 Henry JA, Roberts LE, Caspary DM, Theodoroff SM, Salvi RJ: Underlying mechanisms of tinnitus: review and clinical implications. J Am Acad Audiol 2014;25:5-22; quiz 126.

$\checkmark 5$ Engdahl B, Krog NH, Kvestad E, Hoffman HJ, Tambs K: Occupation and the risk of bothersome tinnitus: results from a prospective cohort study (HUNT). BMJ Open 2012;2:e000512. 
6 Glicksman JT, Curhan SG, Curhan GC: A prospective study of caffeine intake and risk of incident tinnitus. Am J Med 2014;127:739743.

7 Martinez C, Wallenhorst C, McFerran D, Hall DA: Incidence rates of clinically significant tinnitus: 10-year trend from a cohort study in England. Ear Hear 2015;36:e69-e75.

8 Cooper JC Jr: Health and nutrition examination survey of 1971-1975: part II. Tinnitus, subjective hearing loss, and well-being. J Am Acad Audiol 1994;5:37-43.

9 Hoffmann HJ, Reed GW: Epidemiology of Tinnitus; in Snow JB Jr (ed): Tinnitus: Theory and Management. BC Decker, Inc., 2004, pp 16-41.

$>10$ Shargorodsky J, Curhan GC, Farwell WR: Prevalence and characteristics of tinnitus among US adults. Am J Med 2010;123:711718.

11 Oiticica J, Bittar RS: Tinnitus prevalence in the city of São Paulo. Braz J Otorhinolaryngol 2015;81:167-176.

12 Sindhusake D, Mitchell P, Newall P, Golding M, Rochtchina E, Rubin G: Prevalence and characteristics of tinnitus in older adults: the blue mountains hearing study. Int J Audiol 2003;42:289-294.

13 Davis AC: The prevalence of hearing impairment and reported hearing disability among adults in great Britain. Int J Epidemiol 1989; 18:911-917.

14 McCormack A, Edmondson-Jones M, Fortnum H, Dawes P, Middleton H, Munro KJ, Moore DR: The prevalence of tinnitus and the relationship with neuroticism in a middleaged UK population. J Psychosom Res 2014; 76:56-60.

15 Pilgramm M, Rychlick R, Lesbisch H, Siedentop H, Goebel G, Kirchhoff D: Tinnitus in the federal republic of Germany. A Representative Epidemiological Study; in Proceedings of the 6th International Tinnitus Seminar. London, Biddles Short Run Books, 1999, pp 64-67.

16 Hasson D, Theorell T, Westerlund H, Canlon B: Prevalence and characteristics of hearing problems in a working and non-working Swedish population. J Epidemiol Community Health 2010;64:453-460.

-17 Michikawa T, Nishiwaki Y, Kikuchi Y, Saito $\mathrm{H}$, Mizutari K, Okamoto M, Takebayashi T: Prevalence and factors associated with tinnitus: a community-based study of Japanese elders. J Epidemiol 2010;20:271-276.

$\checkmark 18 \mathrm{Xu}$ X, Bu X, Zhou L, Xing G, Liu C, Wang D: An epidemiologic study of tinnitus in a population in Jiangsu Province, China. J Am Acad Audiol 2011;22:578-585.

19 Jalessi M, Farhadi M, Asghari A, Kamrava SK, Amintehran E, Ghalehbaghi S, Heshmatzadeh Behzadi A, Pousti SB: Tinnitus: an epidemiologic study in Iranian population. Acta Med Iran 2013;51:886-891.

20 Park RJ, Moon JD: Prevalence and risk factors of tinnitus: the Korean national health and nutrition examination survey 2010-2011, a cross-sectional study. Clin Otolaryngol 2014; 39:89-94.

21 Park KH, Lee SH, Koo JW, Park HY, Lee KY, Choi YS, Oh KW, Lee A, Yang JE, Woo SY, Kim SW, Cho YS: Prevalence and associated factors of tinnitus: data from the Korean national health and nutrition examination survey 2009-2011. J Epidemiol 2014;24:417-426.

22 Khedr EM, Ahmed MA, Shawky OA, Mohamed ES, El Attar GS, Mohammad KA: Epidemiological study of chronic tinnitus in Assiut, Egypt. Neuroepidemiology 2010;35:4552.

23 Lasisi AO, Abiona T, Gureje O: Tinnitus in the elderly: profile, correlates, and impact in the nigerian study of ageing. Otolaryngol Head Neck Surg 2010;143:510-515.

24 Ottaviani A, Bergomi A, Dacomo G, et al: Eziopatogenesi; in Motta G (ed): Gli Acufeni. Atti LXX Congresso Nazionale della Società Italiana di Otorinolaringoiatria e Chirurgia Cervico-Facciale. Bologna, 1983, pp 25-28.

25 Quaranta A, Assennato G, Sallustio V: Epidemiology of hearing problems among adults in Italy. Scand Audiol Suppl 1996;42:9-13.

26 Fioretti AB, Fusetti M, Eibenstein A: Association between sleep disorders, hyperacusis and tinnitus: evaluation with tinnitus questionnaires. Noise Health 2013;15:91-95.

27 Chiarella G, Bono F, Cassandro C, Lopolito $\mathrm{M}$, Quattrone A, Cassandro E: Bilateral transverse sinus stenosis in patients with tinnitus. Acta Otorhinolaryngol Ital 2012;32:238-243.

28 Martines F, Bentivegna D, Di Piazza F, Martines E, Sciacca V, Martinciglio G: Investigation of tinnitus patients in Italy: clinical and audiological characteristics. Int J Otolaryngol 2010;2010:265861.

29 Monzani D, Genovese E, Marrara A, Gherpelli C, Pingani L, Forghieri M, Rigatelli M, Guadagnin T, Arslan E: Validity of the Italian adaptation of the tinnitus handicap inventory; focus on quality of life and psychological distress in tinnitus-sufferers. Acta Otorhinolaryngol Ital 2008;28:126-134.

-30 Passi S, Ralli G, Capparelli E, Mammone A, Scacciatelli D, Cianfrone G: The THI questionnaire: psychometric data for reliability and validity of the Italian version. Int Tinnitus J 2008;14:26-33.

31 Messano GA, Petti S: General dental practitioners and hearing impairment. J Dent 2012; 40:821-828.

32 Cuda D: Acufeni: diagnosi E terapia. Quaderni monografici di aggiornamento, A.O.O.I. 2004. http://digidownload.libero.it/ait.onlus/ acufe1.pdf (accessed December 27, 2014).

33 Gallus S, Lugo A, Pacifici R, Pichini S, Colombo P, Garattini S, La Vecchia C: E-cigarette awareness, use, and harm perception in Italy: a national representative survey. Nicotine Tob Res 2014;16:1541-1548.

34 Lugo A, Asciutto R, Bosetti C, Parazzini F, La Vecchia C, Gallus S: Regular use of aspirin for cardiovascular disease prevention in Italy. Prev Med 2014;63:48-51.
Mahboubi H, Oliaei S, Kiumehr S, Dwabe S, Djalilian HR: The prevalence and characteristics of tinnitus in the youth population of the United States. Laryngoscope 2013;123:20012008.

36 Fujii K, Nagata C, Nakamura K, Kawachi T, Takatsuka N, Oba S, Shimizu H: Prevalence of tinnitus in community-dwelling Japanese adults. J Epidemiol 2011;21:299-304.

37 Caiazzo A, Cardano M, Cois E, Costa G, Marinacci C, Spadea T, Vannoni F, Venturini L: Inequalities in health in Italy. Epidemiol Prev 2004;28(3 suppl):i-ix, 1-161.

38 Zisook S, Schneider D, Shuchter SR: Anxiety and bereavement. Psychiatr Med 1990;8:8396.

39 Canlon B, Theorell T, Hasson D: Associations between stress and hearing problems in humans. Hear Res 2013;295:9-15.

40 Evans GW, Kantrowitz E: Socioeconomic status and health: the potential role of environmental risk exposure. Annu Rev Public Health 2002;23:303-331.

-41 Nondahl DM, Cruickshanks KJ, Huang GH, Klein BE, Klein R, Nieto FJ, Tweed TS: Tinnitus and its risk factors in the Beaver Dam offspring study. Int J Audiol 2011;50:313320

-42 Corrao G, Bagnardi V, Zambon A, La Vecchia C: A meta-analysis of alcohol consumption and the risk of 15 diseases. Prev Med 2004;38: 613-619.

43 Leong DP, Smyth A, Teo KK, McKee M, Rangarajan S, Pais P, Liu L, Anand SS, Yusuf S: Patterns of alcohol consumption and myocardial infarction risk: observations from 52 countries in the INTERHEART case-control study. Circulation 2014;130:390-398.

44 O’Keefe JH, Bybee KA, Lavie CJ: Alcohol and cardiovascular health: the razor-sharp double-edged sword. J Am Coll Cardiol 2007;50: 1009-1014.

45 De Ridder D, Ryu H, Møller AR, Nowé V, Van de Heyning P, Verlooy J: Functional anatomy of the human cochlear nerve and its role in microvascular decompressions for tinnitus. Neurosurgery 2004;54:381-388; discussion 388-390.

46 McCormack A, Edmondson-Jones M, Mellor D, Dawes P, Munro KJ, Moore DR, Fortnum $\mathrm{H}$ : Association of dietary factors with presence and severity of tinnitus in a middle-aged UK population. PLoS One 2014;9:e114711.

-47 Rossi M, Negri E, Bosetti C, Dal Maso L, Talamini R, Giacosa A, Montella M, Franceschi S, La Vecchia C: Mediterranean diet in relation to body mass index and waist-to-hip ratio. Public Health Nutr 2008;11:214-217.

48 Estruch R, Ros E, Salas-Salvadó J, Covas MI, Corella D, Arós F, Gómez-Gracia E, RuizGutiérrez V, Fiol M, Lapetra J, LamuelaRaventos RM, Serra-Majem L, Pintó X, Basora J, Muñoz MA, Sorlí JV, Martínez JA, Martínez-González MA: Primary prevention of cardiovascular disease with a Mediterranean diet. N Engl J Med 2013;368:12791290. 
49 Turati F, Pelucchi C, Galeone C, Praud D, Tavani $A$, La Vecchia C: Mediterranean diet and non-fatal acute myocardial infarction: a casecontrol study from Italy. Public Health Nutr 2015;18:713-720.

50 Giacosa A, Barale R, Bavaresco L, Gatenby P, Gerbi V, Janssens J, Johnston B, Kas K, La Vecchia C, Mainguet P, Morazzoni P, Negri E, Pelucchi C, Pezzotti M, Rondanelli M: Cancer prevention in Europe: the Mediterranean diet as a protective choice. Eur J Cancer Prev 2013;22:90-95.

-51 Trichopoulou A, Costacou T, Bamia C, Trichopoulos D: Adherence to a Mediterranean diet and survival in a Greek population. N Engl J Med 2003;348:2599-2608.

52 van den Brandt PA: The impact of a Mediterranean diet and healthy lifestyle on premature mortality in men and women. Am J Clin Nutr 2011;94:913-920.

53 Pelucchi C, Galeone C, Negri E, La Vecchia C: Trends in adherence to the Mediterranean diet in an Italian population between 1991 and 2006. Eur I Clin Nutr 2010;64:1052-1056.

54 da Silva R, Bach-Faig A, Raidó Quintana B, Buckland G, Vaz de Almeida MD, Serra-Majem L: Worldwide variation of adherence to the Mediterranean diet, in 1961-1965 and 2000-2003. Public Health Nutr 2009;12: 1676-1684.

55 Stocks SJ, McNamee R, van der Molen HF, Paris C, Urban P, Campo G, Sauni R, Martínez Jarreta B, Valenty M, Godderis L, Miedinger D, Jacquetin P, Gravseth HM, Bonneterre V, Telle-Lamberton M, BensefaColas L, Faye S, Mylle G, Wannag A, Samant
Y, Pal T, Scholz-Odermatt S, Papale A, Schouteden M, Colosio C, Mattioli S, Agius R: Trends in incidence of occupational asthma, contact dermatitis, noise-induced hearing loss, carpal tunnel syndrome and upper limb musculoskeletal disorders in European countries from 2000 to 2012. Occup Environ Med 2015;72:294-303.

56 Geocze L, Mucci S, Abranches DC, Marco MA, Penido Nde O: Systematic review on the evidences of an association between tinnitus and depression. Braz J Otorhinolaryngol 2013;79:106-111.

57 Michikawa T, Nishiwaki Y, Saito H, Mizutari $\mathrm{K}$, Takebayashi T: Tinnitus preceded depressive symptoms in community-dwelling older Japanese: a prospective cohort study. Prev Med 2013;56:333-336. 